\title{
EFEITOS DE SISTEMAS DE PREPARO DO SOLO NA EROSÃO E NA PRODUTIVIDADE DA ACÁCIA-NEGRA (Acacia mearnsii De Wild.)
}

\section{EFFECTS OF SOIL TILLAGE SYSTEMS ON SOIL EROSION AND ON BLACK WATTLE (Acacia mearnsii De Wild.) PRODUCTIVITY}

\author{
Renato A. Dedecek ${ }^{1}$ Gustavo R. Curcio ${ }^{2}$ Marcos F. G. Rachwal ${ }^{2} \quad$ Augusto A. Simon $^{3}$ \\ RESUMO
}

Os plantios homogêneos de acácia-negra nem sempre são feitos em solos adequados às exigências da espécie, seja pelo valor da terra ou proximidade da indústria. Diferentes sistemas de preparo podem melhorar as condições do solo, evitar problemas de erosão e diminuir custos de implantação. Em áreas de propriedade da TANAGRO S.A e da SETA S.A., nos municípios de Piratini e Butiá, RS, em dois tipos de solos distintos - Neossolo Litólico e Argissolo Vermelho-Amarelo, foram testados sistemas de preparo do solo com diferentes níveis de movimentação para plantio de acácia-negra: plantio de mudas em covas e plantio após subsolagens com duas, três e cinco hastes e uso de gradagens. Foram avaliados o crescimento em DAP e altura, anualmente, e produção de biomassa aérea no corte raso. Os solos foram caracterizados química e fisicamente em seus horizontes superficiais. Nas plantas, após sete anos, foram coletadas amostras de discos em seis posições no tronco para avaliação das densidades básicas. Preparo do solo com subsolador de cinco hastes apresentou maiores perdas de solo, que foram mensuráveis apenas até 18 meses após o plantio. Essas perdas de solo são extremamente importantes na sustentabilidade da produção do Neossolo Litólico, composto em $80 \%$ de calhaus e cascalho. O preparo reduzido do solo, com a abertura de covas manual e mecanicamente para plantio da acácia negra, não diminuiu o crescimento das plantas em ambos os solos estudados. No entanto, o desenvolvimento inicial das plantas de acácia negra, plantadas em sistema de preparo reduzido, foi mais lento (altura e DAP), defasagem que permaneceu até os 24 meses após o plantio.

Palavras-chave: características físico-hídricas do solo; perdas de solo; cultivo mínimo.

\section{ABSTRATC}

Black wattle plantations are not always settled in soils adequate for the species sometimes due to land value or due to industry distance. Different soil tillage systems can improve soil conditions to plant growth, avoid erosion problems and reduce costs. In areas belonging to TANAGRO S.A. e SETA S.A., in two different counties, Piratini and Butiá, RS, and two distinct soil types - litholic and red yellow podzolic soil tillage systems with different levels of soil disturbance were tested in growing black wattle: planting in holes with no-tillage and planting after subsoiling with two, three and five shranks and harrowings. Plant height and DBH were taken annually, and after seven years samples of the trunk were obtained at six different positions for specific gravity analyses. Soils were characterized chemically and physically on their surface layers. Soil losses were greater where soil was prepared with a five-shrank-subsoiler, and they were measurable until 18 months after planting. These soil losses are very important for sustainable production of the litholic soil, constituted in around $80 \%$ of stones. Reduced tillage system, with planting holes opened manually and mechanically, did not decrease black wattle growth on both soils studied. However, plant growth increment at the initial stage was smaller on reduced tillage system, and this difference to the other tillage systems tested remained until 24 months after planting.

Keywords: soil physical characteristics; erosion soil losses; minimum tillage.

\section{INTRODUÇÃO}

O aumento e/ou a manutenção da produtividade de uma espécie florestal como a acácia negra depende da determinação e da proposição de alternativas aos fatores bióticos e abióticos, limitantes ao

1. Engenheiro Agrônomo, Ph.D., Pesquisador da Embrapa Florestas, Caixa Postal 391, Estrada da Ribeira, km 111, CEP 83411-000, Colombo (PR). dedecek@cnpf.embrapa.br

2. Engenheiro Agrônomo, MSc., Pesquisador da Embrapa Florestas, Caixa Postal 391, Estrada da Ribeira, km 111, CEP 83411-000, Colombo (PR). sac@cnpf.embrapa.br

3. Engenheiro Florestal, Técnico Responsável pelo Setor Florestal da TANAGRO, Empresa do Grupo TANAC S.A., Rua Torbjorn Weibull, 199, CEP 95780-000, Montenegro (RS). aasimon@tanac.com.br

Recebido para publicação em 26/04/2005 e aceito em 6/06/2007. 
desenvolvimento da cultura e seleção do material genético mais adequado para cada região edafo-climática, aliadas ao uso de técnicas silviculturais viáveis sob os pontos de vista técnico, econômico, social e ambiental.

Segundo Donkin (1994), a profundidade efetiva do solo foi claramente a variável mais importante no crescimento da acácia negra, na tentativa de estabelecer o potencial produtivo dos sítios. Não é apenas a profundidade em si que permite um bom desenvolvimento das árvores de um ponto de vista fisiológico, mas as complexas interações e associações com umidade do solo, clima e material de origem do solo.

O plantio de acácia-negra ocorre no Rio Grande do Sul, desde a região da Serra Gaúcha, passando pela Depressão Central e estendendo-se mais recentemente até a Serra do Sudeste, estimando-se a área total plantada em 160.000 ha (MAESTRI et al., 1987). Dados mais recentes estimam a área plantada com acácianegra no Brasil em 140 mil hectares (TONIETTO e STEIN, 1997), com uma taxa anual de plantio de 20.000 ha (SIMON, 1999).

De acordo com o "Institute for Commercial Forestry Research - ICFR", da África do Sul (ICFR, 1991), as operações silviculturais mais importantes são fertilização e bom controle de plantas daninhas. Segundo Spoor (1975), a planta não responde diretamente aos implementos de preparo do solo, mas ao ambiente criado no solo, que favoreça a movimentação da água, aração e disponibilidade de nutrientes. Operações de preparo do solo demandam energia, tempo e custos, que aumentam rapidamente com a profundidade de trabalho e o número de operações. Assim, o custo da subsolagem é quase o dobro do custo de uma aração profunda e o quádruplo de uma aração normal (HILLEL, 1980).

Segundo Mazuchowski e Derpsch (1984), o preparo do solo varia de acordo com as características dos solos, clima e com a finalidade a que se destina: eliminação de plantas daninhas ou eliminação de camadas de solo compactadas. A adoção de técnicas de preparo do solo, quando após as operações de corte raso, visa ainda restaurar suas características físico-hídricas, garantindo o pleno desenvolvimento da segunda rotação, permitindo um melhor crescimento das raízes, incorporação de restos da colheita (galhos, cascas, pedaços de madeira) e adubo, contribuindo assim para a sustentabilidade da produção florestal.

O escarificador e o subsolador estão entre os equipamentos mais usados para o estabelecimento e recuperação de plantações florestais, pois são operações que melhoram a sobrevivência e o crescimento das mudas, uma vez que propiciam o alcance de profundidades maiores pelas raízes. Também expõem menor área de solo e não promovem o revolvimento do mesmo, reduzindo o risco de erosão nos plantios florestais, entre a fase de plantio e cobertura do solo. Vásquez (1987), trabalhando com bracatinga (Mimosa scabrella), constatou que o crescimento em altura, diâmetro da base e diâmetro da copa das plantas foi influenciado no primeiro ano pelos tratamentos de preparo do solo, porém este efeito desapareceu no decorrer do segundo ano. Em área de reforma com Eucalyptus grandis, maior produção de biomassa foi associada ao maior revolvimento no preparo do solo aos 38 meses após o plantio, sendo este maior crescimento creditado à maior disponibilização de nutrientes e à redução das plantas competidoras (GATTO et al., 2003). Já para Stape et al (2002), até 48 meses após o plantio de um clone de Eucalyptus grandis $x$ urophyla, não houve diferença de crescimento para subsolagem comparada ao coveamento, em Latossolo de textura média.

Foram objetivos deste trabalho a redução do preparo do solo e a conseqüente redução nos custos de implantação e nas taxas de erosão hídrica do solo para permitir condições de desenvolvimento e produtividade das plantas e sustentabilidade do sítio.

\section{MATERIAL E MÉTODOS}

\section{Delineamento experimental}

Os sistemas de preparo foram em faixa, para facilitar as operações, arranjados em blocos ao acaso com três repetições. As parcelas foram constituídas de 5 linhas com 20 plantas em cada linha, considerandose como área útil as três linhas centrais com 18 plantas cada.

\section{Implantação}

Foram instalados dois experimentos, em maio de 1995, em áreas de plantio comercial de acácianegra, no município de Butiá, RS, da empresa SETA S.A., e, no município de Piratini, RS, pertencente à TANAGRO S.A. O município de Piratini está situado a $31^{\circ} 15^{\prime}$ de latitude sul e $53^{\circ} 13^{\prime}$ de longitude oeste, a 350 m de altitude, com precipitação média anual de 1400 mm. O município de Butiá está situado a 3007’ de 
latitude sul e $50^{\circ} 57^{\prime}$ de longitude oeste, a 70 m acima do nível do mar.

Os tratamentos testados no município de Butiá, em Argissolo Vermelho-Amarelo alissólico (subgrupo não contemplado por Embrapa (1999)) abrúptico A proeminente epidistrófico A proeminente textura média/argilosa relevo ondulado, foram os seguintes:

1. 3H - consta de uma passada de grade pesada, seguida de uma subsolagem com subsolador de três hastes (largura de trabalho - 0,90 m) e uma passada de grade encosteladora (até seis meses após o plantio); abertura de covas, colocação de adubo e calcário e plantio das mudas feito manualmente;

2. $2 \mathrm{H}$ - consta de uma passada de grade pesada, seguida de uma subsolagem com duas hastes (largura de trabalho - 0,45 m) e grade encosteladora (até seis meses após o plantio) e demais operações idênticas ao anterior;

3. PC - abertura de covas manual (com pá) com dimensões de 30 x 30 x $30 \mathrm{~cm}$, em solo nãopreparado, e as operações de calagem adubação e plantio como nos anteriores (plantio em cova).

No município de Piratini, em Neossolo Litólico Tb Distrófico típico A proeminente textura argilosa cascalhenta fase pedregosa relevo forte ondulado substrato xisto, foram testados os mesmos preparos descritos para Butiá, acrescidos do seguinte:

4. $5 \mathrm{H}$ - consta de uma subsolagem com subsolador de cinco hastes (largura de trabalho - 1,80 m), seguida de uma gradagem com grade leve, uma subsolagem com subsolador de três hastes e uma passada de grade encosteladora (até seis meses após o plantio) e as demais operações de adubação, calagem e plantio, como nos anteriores.

5. PC - abertura das covas (com $50 \mathrm{~cm}$ de profundidade por um diâmetro de $50 \mathrm{~cm}$ ) no Neossolo Litólico, Piratini, realizada mecanicamente através do uso de broca acionada pela tomada de força do trator.

O preparo do solo foi feito apenas nas linhas de plantio, sendo o espaçamento entre linhas de $3 \mathrm{~m}$ e 1,50 entre plantas, com parcelas de $15 \mathrm{~m}$ de largura por $30 \mathrm{~m}$ de comprimento no sentido do declive. Para a correção da acidez, foram colocados 100 g de calcário dolomítico (PRNT 100\%) por cova, e, para o crescimento inicial das mudas, foram colocados $80 \mathrm{~g}$ por cova da fórmula 7-30-15, seguindo prática adotada pelas empresas.

\section{Determinações das características dos solos}

Os solos foram amostrados após as operações de preparo do solo para análises químicas e físicohídricas, nas profundidades de: 0 a 10, 10 a 20 e 20 a $30 \mathrm{~cm}$ e 40 a $50 \mathrm{~cm}$ apenas no município de Butiá, RS, em pequenas trincheiras de até $60 \mathrm{~cm}$ de profundidade. As amostras de solo indeformadas foram obtidas pelo uso de anéis metálicos de 5,3 cm de diâmetro por $3 \mathrm{~cm}$ de altura. Devido à grande quantidade de cascalhos e calhaus no Neossolo Litólico de Piratini, foi impossível obter amostras indeformadas de solo para proceder as análises físico-hídricas, como as realizadas em Butiá. As análises químicas e físico-hídricas foram realizadas nos laboratórios da Embrapa Florestas e seguem metodologia descrita em EMBRAPA (1997).

Foram instaladas rodas amostradoras de enxurrada (PARSONS, 1954) para quantificar as perdas de solo, uma para cada sistema de preparo, armazenando-se as amostras em caixas de $250 \mathrm{l}$, coletadas mensalmente ou a cada $100 \mathrm{~mm}$ de chuvas, quando as chuvas fossem maiores do que $100 \mathrm{~mm}$ por mês.

\section{Determinações das características das plantas}

Anualmente, nos primeiros três anos, as plantas foram medidas em altura e DAP, medições repetidas nos quinto e sétimo anos após o plantio. Em Butiá, a exploração das acácias ocorreu antes de completarem sete anos (2002), idade normalmente usada para colheita, o que impediu de serem apresentados os dados dendométricos finais para este sítio. No município de Piratini, no corte raso, foram abatidas três árvores por tratamento e coletados discos de seis posições diferentes do tronco comercial (base, DAP, 25, 50, 75 e 100\% da altura comercial, considerando-se diâmetro mínimo do tronco de $5 \mathrm{~cm}$ ), sendo também determinada a massa específica básica, em todos os discos, pelo método da pesagem (VITAL, 1984). Nesta ocasião, foram selecionadas três árvores do plantio comercial que circundava a área experimental para as mesmas avaliações, para comparações com o sistema de preparo e plantio adotado pelas empresas (testemunha). 


\section{RESULTADOS E DISCUSSÃO}

Na Tabela 1, estão computadas as horas de trator gastas em cada sistema de preparo do solo, com exceção do encostelamento, que visa criar um camalhão na linha de plantio, porque essa operação foi realizada diferentemente nos dois locais. Enquanto, na região de Butiá, foi feita junto com a subsolagem; em Piratini, foi realizada até seis meses após o plantio. Mesmo assim, a redução de trabalho de preparo do solo com o plantio direto seria de dois terços, comparando-se ao preparo $5 \mathrm{H}$. Tal operação de abertura mecânica de covas foi realizada nas condições deste experimento com a mesma broca usada para abertura de covas para a colocação de moirões. Moreira (1995), testando um protótipo desenvolvido para esse tipo de operação de abertura de covas para plantio de mudas florestais, computou, em 0,75 horas ha $^{-1}, 0$ tempo necessário, o qual, no entanto, se computados os problemas do protótipo testado, poderia chegar a 4,5 horas ha ${ }^{-1}$. Este valor foi mantido na Tabela 1, considerando que os testes referidos acima foram realizados em solo arenoso e sem pedregosidade, permitindo um rendimento maior e um desgaste menor da máquina, o que não é a realidade da maioria dos plantios de acácia-negra na região sudeste do RS.

TABELA 1: Horas de operação de trator para preparo do solo para plantio de acácia negra.

TABLE 1: Hours of tractor operation to till the soil to the planting of black wattle.

\begin{tabular}{|c|c|c|c|c|}
\hline \multirow{3}{*}{ Operações } & \multicolumn{4}{|c|}{ Sistemas de Preparo } \\
\hline & $5 \mathrm{H}$ & $3 \mathrm{H}$ & $2 \mathrm{H}$ & PC \\
\hline & \multicolumn{4}{|c|}{$\mathrm{h} \mathrm{ha}^{-1}$} \\
\hline Subsolagem com 5 hastes & 4,5 & - & - & - \\
\hline Subsolagem com 3 hastes & 4,5 & 4,5 & - & - \\
\hline Subsolagem com 2 hastes & - & - & 3,5 & - \\
\hline Gradagem com grade pesada & - & 3,5 & 3,5 & - \\
\hline Gradagem com grade leve & 3 & - & - & - \\
\hline Abertura mecânica de covas & - & - & - & 4,5 \\
\hline Total & 12 & 8 & 7 & 4,5 \\
\hline
\end{tabular}

OBS: Trator usado com potência de acordo com a demandada pela operação realizada.

Os dados de algumas características físico-hídricas mostrados na Tabela 2, que correspondem ao sistema de plantio em cova (PC), são os valores que o solo apresenta naturalmente, enquanto os valores dos outros sistemas foram obtidos após a subsolagem e outras operações características de cada sistema. Como a subsolagem normalmente atinge no máximo $40 \mathrm{~cm}$ de profundidade, a profundidade de amostragem de 40 a $50 \mathrm{~cm}$ pouco foi afetada por esta operação de preparo do solo, camada naturalmente mais adensada, pois se trata de um solo com horizonte B textural.

TABELA 2: Algumas características físico-hídricas de um Argissolo Vermelho-Amarelo de Butiá, RS, após operações de preparo do solo.

TABLE 2: Soil physical characteristics of a Red Yellow Podzolic from Butiá, RS, after soil tillage to planting.

\begin{tabular}{l|c|c|c|c|cc}
\hline $\begin{array}{c}\text { Sistemas } \\
\text { de Preparo }\end{array}$ & Profundidade & $\begin{array}{c}\text { Água } \\
\text { Disponível } \\
(\%)\end{array}$ & $\begin{array}{c}\text { Densidade } \\
\text { do Solo } \\
\left(\mathrm{kg} \mathrm{dm}^{-3}\right)\end{array}$ & $\begin{array}{c}\text { Permeabilidade } \\
\text { Saturada } \\
\left(\mathrm{cm} \mathrm{h}^{-1}\right)\end{array}$ & \multicolumn{2}{|c}{ Porosidade } \\
\cline { 7 - 8 } & $(\mathrm{cm})$ & & Total (\%) & Macro (\%) \\
\hline $3 \mathrm{H}$ & $0-10$ & 5,6 & 1,28 & $>25,0$ & 51 & 29 \\
& $40-50$ & 7,2 & 1,49 & 0,58 & 42 & 12 \\
\hline $\mathrm{H}$ & $0-10$ & 5,8 & 1,26 & $>25,0$ & 52 & 31 \\
& $40-50$ & 6,4 & 1,19 & 0,07 & 54 & 17 \\
\hline P C & $0-10$ & 5,9 & 1,46 & 1,71 & 44 & 12 \\
& $40-50$ & 4,8 & 1,40 & 0,21 & 46 & 6 \\
\hline
\end{tabular}

Observa-se, na Tabela 2, que houve uma modificação da estrutura do solo nos sistemas de preparo com subsolador de duas ou três hastes, principalmente na camada superficial, tornando-se menos denso, mais permeável e mais poroso, o que não se traduziu em um aumento de água disponível, uma característica sempre desejável. Contudo, inicialmente, aumentou muito a permeabilidade saturada da camada superficial, o que favoreceu a infiltração da água da chuva no solo, reduzindo o volume da enxurrada e, 
conseqüentemente, a erosão.

Observa-se, na Figura 1, que, inicialmente, o revolvimento de preparo do solo resultou em uma maior infiltração da água da chuva com conseqüente menor erosão, segundo os dados de perdas de solo obtidos no município de Piratini, RS, em 05/07/95 (Figura 1). Desta forma, as perdas de solo dos tratamentos com subsolagem ( $3 \mathrm{H}$ e $2 \mathrm{H}$ ) foram menores no primeiro mês das avaliações do que no sistema de abertura de covas (PC). Nas outras datas, o sistema de plantio direto apresentou menores perdas de solo que os sistemas com maior revolvimento do solo, conseqüência do acomodamento do solo revolvido inicialmente, que ocorre naturalmente.

Saliente-se que o preparo do solo com três hastes (3H, Figura 1 ) apresentou os valores de perdas de solo muito mais próximos aos do plantio em covas (PC) do que aos demais preparos. As perdas de solo apresentadas pelo sistema de preparo com subsolador de 2 hastes $(2 \mathrm{H})$ foi muito acima do esperado, talvez pela dificuldade em aprofundar o subsolador neste sistema, diminuindo a infiltração da água da chuva, aliado a uma faixa de preparo com largura semelhante ao do preparo com 3 hastes. Segundo Edeso et al. (1999), em plantios florestais com aração, a remoção dos resíduos e da cobertura vegetal quadruplicou as perdas de solo quando comparado com área sem preparo mecânico, no período do corte raso de plantio de Pinus radiata e do estabelecimento da vegetação de sub-bosque. Silva et al. (1998) reportaram perdas de solo de $35 \mathrm{~kg} \mathrm{ha}^{-1}$, após corte raso de acácia negra com manutenção dos resíduos da colheita na superfície do solo, num período de dez meses (janeiro a outubro). Com a queima dos resíduos, os mesmos autores obtiveram perdas de solo de 9,2 tha ${ }^{-1}$. Os resultados deste trabalho mostram perdas de solo de $540 \mathrm{~kg} \mathrm{ha}^{-1}$ num período de 14 meses no sistema de preparo com abertura de covas (PC), que seria a condição mais aproximada do tratamento reportado por Silva et al. (1999). No mesmo período, as perdas de solo somaram $1135 \mathrm{~kg} \mathrm{ha}^{-1}$ no sistema de preparo com subsolador de 5H, aproximadamente o dobro do ocorrido no sistema PC (Figura 1).

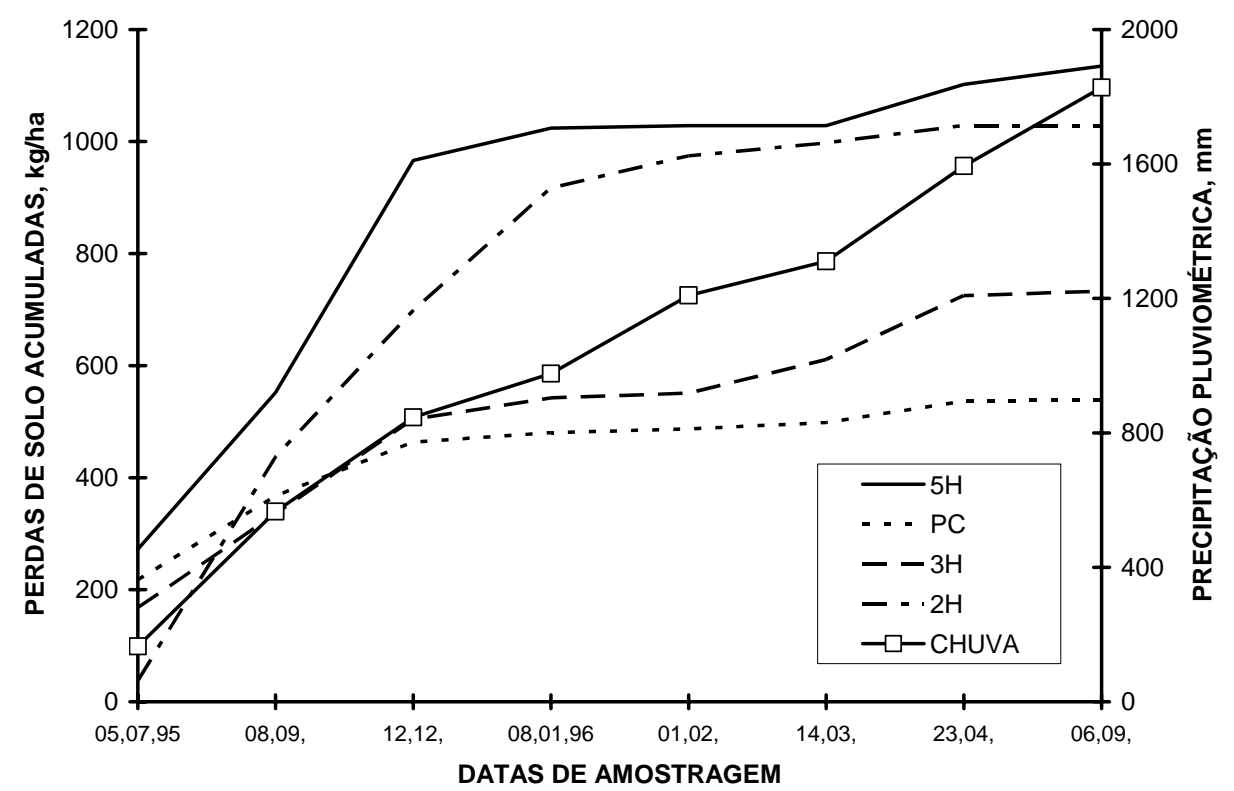

FIGURA 1: Perdas de solo acumuladas medidas em plantios de acácia-negra no período de 05.07 .95 a 06.09.96, por sistema de preparo do solo, em Piratini, RS, 1996.

FIGURE 1: Cumulative soil erosion losses in black wattle plantings from 05.07.95 to 06.09.96, for different soil tillage systems, in Piratini, RS, 1996.

Outra observação importante é a estabilidade que as curvas de perdas de solo de todos os sistemas de preparo do solo apresentam com o passar do tempo (12.12 a 8.1.96), produto do crescimento das árvores e da vegetação nativa, com conseqüente cobertura do solo, além do próprio acomodamento natural do solo.

Em Butiá, RS, no mesmo tipo de solo do estudo realizado por Silva et al. (1998), as perdas de solo em sistema de abertura de covas, considerando-se apenas o período de outubro de 1995 a fevereiro do ano seguinte, foram de $137 \mathrm{~kg} \mathrm{ha}^{-1}$ (Figura 2), muito próximas às medidas em Piratini, RS (120 kg ha ${ }^{-1}$ (Figura 
1). Da mesma forma, as maiores perdas de solo, em Butiá (452 $\left.\mathrm{kg} \mathrm{ha}^{-1}\right)$, para o sistema de preparo do solo com subsolador de 3 hastes $(3 \mathrm{H})$, foram muito semelhantes às registradas em Piratini (383 $\left.\mathrm{kg} \mathrm{ha}^{-1}\right)$, no mesmo período descrito acima. Os solos destes dois locais, embora pertençam a classes diferentes, em termos de erosão, apresentam a mesma limitação de profundidade do horizonte superficial, enquanto um é limitado pela presença da rocha matriz, no outro, ocorre um horizonte de acumulação de argila muito próximo da superfície, que limita a infiltração da água da chuva. Em ambos os locais, as perdas de solo não foram maiores, porque se trata do primeiro plantio em área de campo nativo, onde as gramíneas protegem o solo na faixa não trabalhada (de 1,5 m) pelos implementos usados.

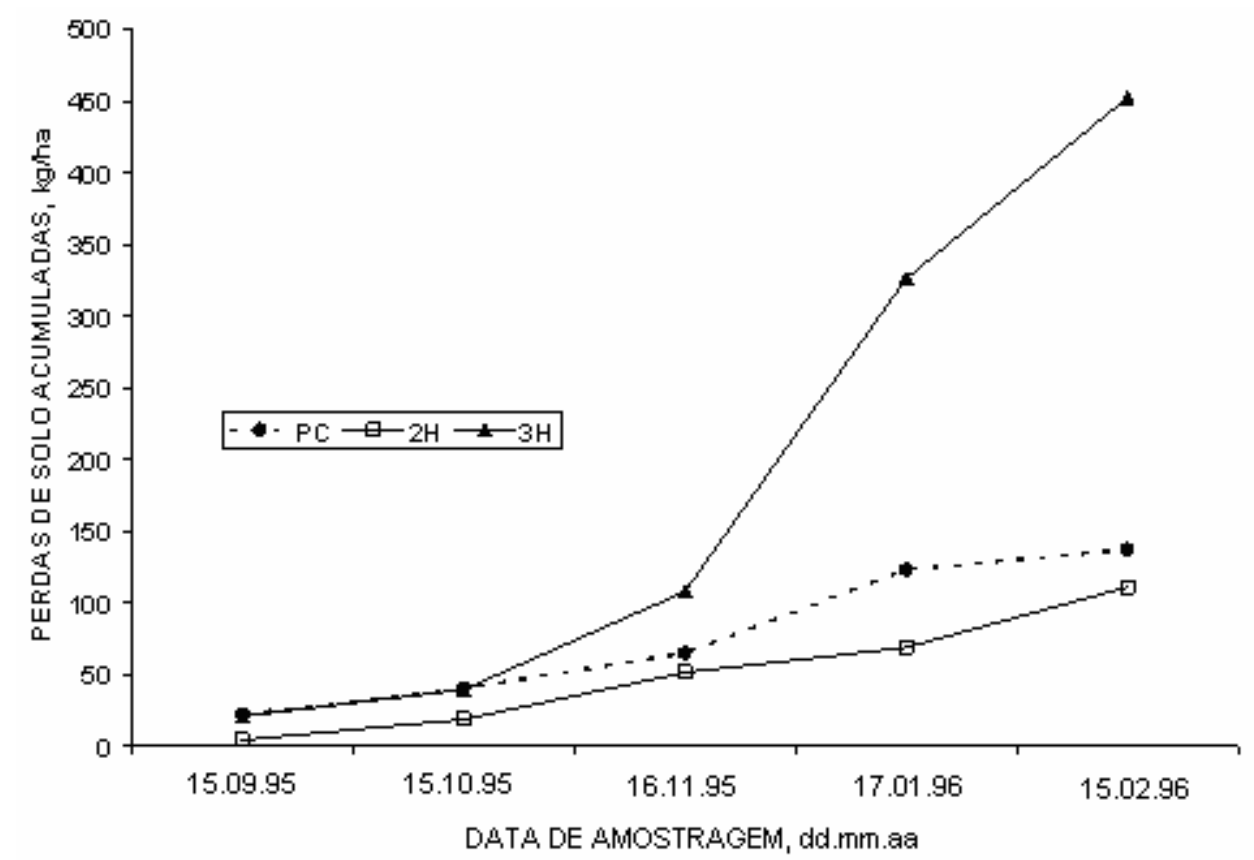

FIGURA 2: Perdas de solo acumuladas coletadas mensalmente entre 15.09.95 a 15.02.96, em plantio de acácia-negra, por sistema de preparo do solo, em Butiá, RS, 1996.

FIGURE 2: Cumulative soil erosion losses in black wattle plantings from 15.09.95 to 15.02.96, for different soil tillage systems, in Butiá, RS, 1996.

Estas mesmas comprovações são constatadas na Figura 3, que mostra a concentração de sedimentos na enxurrada, de acordo com cada sistema de preparo amostrado. Observa-se que, na data de 05/07/95, em Piratini-RS, a concentração de sedimentos na enxurrada foi aproximadamente à mesma para todos os sistemas, pesando, no resultado final das perdas de solo por área, a quantidade da enxurrada maior nos sistemas em que o solo não foi revolvido. O incremento exagerado observado nas perdas de solo nas datas seguintes é função da diminuição da infiltração e aumento da precipitação pluviométrica (Figura 3), com conseqüente aumento da enxurrada e da concentração de sedimentos na enxurrada (Tabela 2).

Observa-se, ainda na Figura 3, que os picos de chuva e de concentração do solo na enxurrada não são evidentes para todos os preparos do solo. A presença de muitas pedras na superfície do solo aumenta a rugosidade e defasagem entre a liberação das partículas de solo e o seu arraste até o ponto de coleta. 


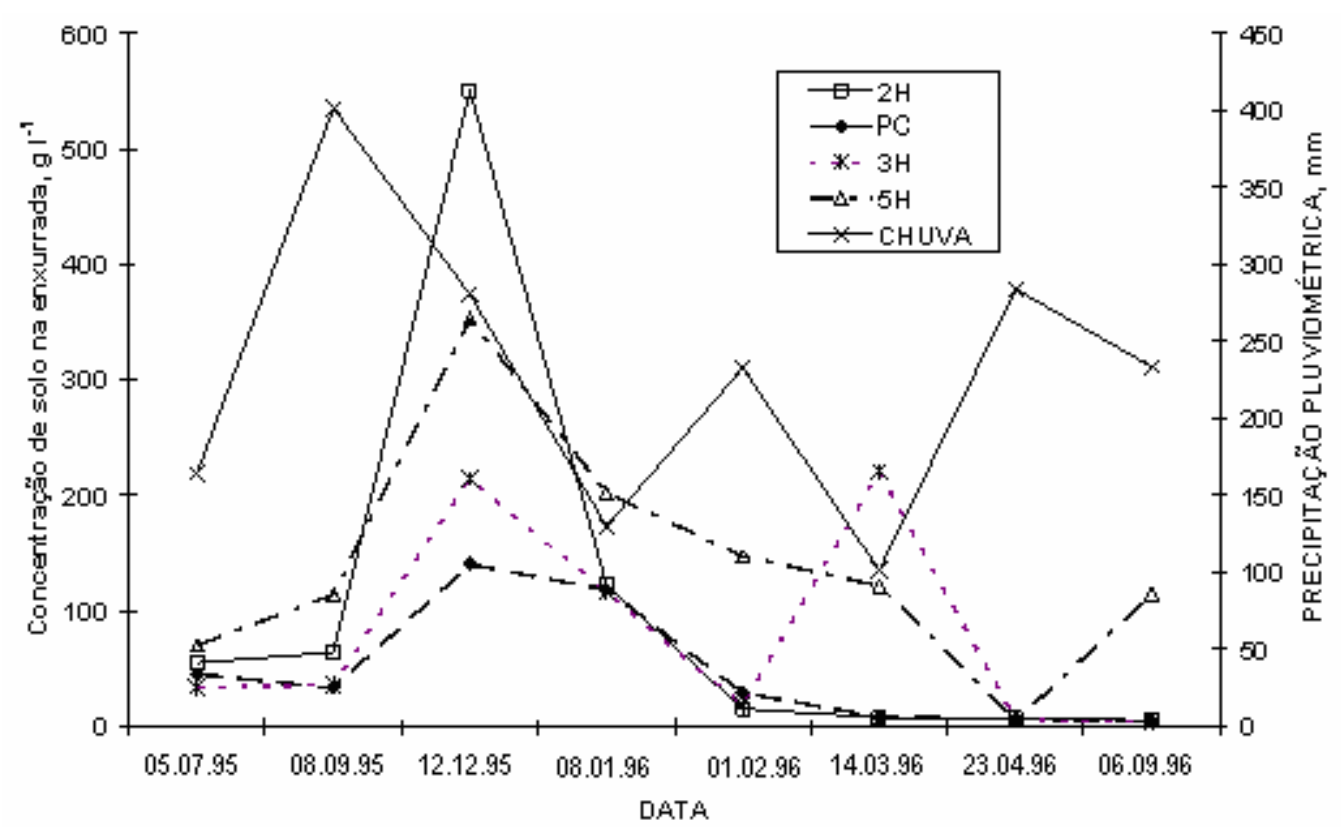

FIGURA 3: Concentração de solo na enxurrada coletada em plantios de acácia-negra, no período de 05.07.95 a 06.09.96, por sistema de preparo do solo, em Piratini, RS, 1996.

FIGURE 3: Soil concentration in runoff water from black wattle plantings from 05.07.95 to 06.09.96 for different soil tillage systems, in Piratini, RS, 1996.

Além da importância ambiental do problema da erosão hídrica do solo, existe o prejuízo que pode advir da perda da camada superficial do solo, normalmente a mais rica em nutrientes e matéria orgânica e com as melhores condições físico-hídricas para o desenvolvimento das raízes. Dois agravantes ocorrem no Neossolo Litólico de Piratini, RS neste aspecto: quase 80\% deste solo (Tabela 3) é formado por calhaus e cascalhos e sua profundidade efetiva não ultrapassa $20 \mathrm{~cm}$. Com a erosão hídrica não controlada, estas áreas terão o pouco de solo que têm, arrastado, e sua profundidade efetiva reduzida com o passar dos anos, comprometendo a manutenção ou o aumento da produtividade da acácia-negra neles. Este é um prejuízo sério, quando se trata de áreas compradas, onde se pretende continuar com o cultivo de acácia-negra por muitos ciclos.

Dezoito meses após o plantio, foi suspensa a amostragem de enxurrada, porque, em nenhum dos sistemas de preparo, houve produção de quantidade suficiente, concluindo-se que, neste período, a cobertura do solo, seja pelas gramíneas nativas ou as acácias, foi suficiente para evitar a erosão.

TABELA 3: Granulometria do Argissolo Vermelho-Amarelo e do Neossolo Litólico de dois municípios do RS.

TABLE 3: Particle size distribution in Red Yellow Argissolo and in Neossolo Litólico from two different sites in RS.

\begin{tabular}{c|c|c|c|c|c|c}
\hline Solos & $\begin{array}{c}\text { Profundidade } \\
(\mathrm{cm})\end{array}$ & Calhaus & Cascalho & Areia & Silte & Argila \\
\cline { 3 - 7 } & \multicolumn{5}{c}{$\left(\mathrm{g} \mathrm{kg}^{-1}\right)$} \\
\hline Argissolo & $0-10$ & 0 & 148 & 526 & 145 & 181 \\
& $40-50$ & 0 & 186 & 275 & 163 & 376 \\
\hline Neossolo & $0-10$ & 298 & 480 & 75 & 64 & 99 \\
\hline
\end{tabular}

Conforme pode ser observado na Tabela 4, apenas o plantio em covas teve perdas de solo com granulometria mais aproximada do original do solo, enquanto nos demais sistemas de preparo do solo os sedimentos produzidos apresentam proporcionalmente mais terra fina do que cascalhos. Em termos químicos, observa-se apenas uma maior concentração do elemento fósforo e de cálcio + magnésio nos sedimentos. Isto ocorre em função da adubação em covas feita no plantio, o que não deixa de ser grave, porque se trata de uma adição de insumo perdido posteriormente pela erosão. 
TABELA 4: Média dos dados das análises químicas e granulométricas dos sedimentos coletados em 14/03 e 23/04/96 e do solo original das parcelas, por sistema de preparo do solo, em Piratini, RS.

TABLE 4: Chemical and textural characteristics of the sediment produced on 14.03 and on 23.04 .96 and of the original soil plots, for different soil tillage systems, in Piratini, RS, 1996.

\begin{tabular}{|c|c|c|c|c|c|c|c|c|c|}
\hline \multirow[t]{3}{*}{ Trat. } & \multicolumn{5}{|c|}{ Características químicas } & \multicolumn{4}{|c|}{ Granulometria } \\
\hline & \multirow{2}{*}{$\frac{\mathrm{pH}}{\left(\mathrm{CaCl}_{2}\right)}$} & $\mathrm{Ca}+\mathrm{Mg}$ & $\mathrm{K}$ & \multirow{2}{*}{$\begin{array}{c}\mathrm{P} \\
\left(\mathrm{mg} \mathrm{dm}^{-3}\right)\end{array}$} & \multirow{2}{*}{$\begin{array}{l}\text { C org. } \\
\left(\mathrm{g} \mathrm{dm}^{-3}\right)\end{array}$} & Cascalho & Areia & Silte & Argila \\
\hline & & (c.molc & $\left.\mathrm{m}^{-3}\right)$ & & & \multicolumn{4}{|c|}{$(\%)$} \\
\hline $5 \mathrm{H}$ & $\overline{5,2}$ & 8,5 & 0,50 & 8,5 & 41 & 44,3 & 17 & 38 & 45 \\
\hline $3 \mathrm{H}$ & 5,1 & 9,6 & 0,66 & 9,0 & 41 & 12,8 & 14 & 37 & 49 \\
\hline $2 \mathrm{H}$ & 5,0 & 9,7 & 0,68 & 6,0 & 41 & 12,0 & 10 & 39 & 51 \\
\hline PC & & & & & & 76,3 & 36 & 24 & 40 \\
\hline Solo & 4,6 & 7,5 & 0,71 & 2,5 & 33 & 77,8 & 23 & 31 & 46 \\
\hline
\end{tabular}

OBS: Não foi obtida quantidade de solo suficiente para proceder a análise química dos sedimentos produzidos com 0 plantio direto.

A menor percentagem de sobrevivência das acácias (Tabela 5) ocorreu no plantio direto em Butiá, RS, onde foram abertas covas de $20 \times 20 \times 20 \mathrm{~cm}$ com a pá, as quais permaneceram cheias de água durante grande período antes e após o plantio. O mesmo sistema, em Piratini, RS, fazendo-se uso da broca mecânica para a abertura das covas, apresentou o maior índice de sobrevivência.

Embora as diferenças sejam muito pequenas, tanto de altura como de DAP, pode-se observar que o desenvolvimento das plantas nos preparos reduzidos (2H e PC) foi maior em Butiá, quando se compara em cada local o crescimento proporcionado pelos diferentes sistemas de preparo do solo. É importante salientar que não houve diferença estatística nos dados de desenvolvimento das acácias para os diferentes sistemas de preparo nos dois locais estudados.

TABELA 5: Percentual de sobrevivência médio de acácias, segundo o sistema de preparo do solo, em dois locais, 1997.

TABLE 5: Percentage of black wattle survival for each soil tillage system in both sites, 1997.

\begin{tabular}{l|c|c|c|c}
\hline \multirow{2}{*}{ Local } & $5 \mathrm{H}$ & $3 \mathrm{H}$ & $2 \mathrm{H}$ & PC \\
\cline { 2 - 5 } & \multicolumn{4}{|c}{ Sobrevivência (\%) } \\
\hline Butiá-RS & - & 85,2 & 93,2 & 77,8 \\
Piratini-RS & 95,1 & 95,7 & 94,4 & 96,9 \\
\hline
\end{tabular}

No entanto, a diferença foi significativa para os parâmetros altura e DAP (Tabela 6), quando se compara a média de crescimento das árvores nos dois locais distintos, com um nível de significância de 1\%, pelo teste de Tukey. Pode-se inferir que esta espécie responde melhor à fertilidade natural do solo, maior no Neossolo Litólico de Piratini, do que à profundidade efetiva do solo para enraizamento, maior no Argissolo de Butiá, devido a se tratar de espécie pioneira.

TABELA 6: Dados de altura e DAP das acácias-negras plantadas em diferentes sistemas de preparo do solo, em dois locais do RS, em 2000 e 2002.

TABLE 6: Data of height and DBH of black wattle plants growing on different soil tillage systems in two sites, in 2000 and 2002.

\begin{tabular}{|c|c|c|c|c|c|c|c|c|c|c|c|}
\hline \multirow{3}{*}{ Local } & \multirow{3}{*}{ Ano } & \multicolumn{10}{|c|}{ Sistemas de Preparo do Solo } \\
\hline & & $5 \mathrm{H}$ & $3 \mathrm{H}$ & $2 \mathrm{H}$ & PC & $\mathrm{M}$ & $5 \mathrm{H}$ & $3 \mathrm{H}$ & $2 \mathrm{H}$ & PC & $M$ \\
\hline & & \multicolumn{5}{|c|}{ Altura (m) } & \multicolumn{5}{|c|}{ DAP $(\mathrm{cm})$} \\
\hline Butiá & 2000 & - & 11,4 & 11,6 & 11,8 & $11,6 b$ & - & 9,5 & 9,8 & 9,8 & $9,7 b$ \\
\hline Piratini & 2000 & 13,0 & 12,8 & 12,7 & 12,4 & $12,7 \mathrm{a}$ & 10,9 & 10,8 & 10,7 & 10,4 & $10,7 \mathrm{a}$ \\
\hline Piratini & 2002 & 17,7 & 18,1 & 18,1 & 17,9 & & 12,9 & 12,8 & 12,9 & 12,7 & \\
\hline
\end{tabular}

Obs: Médias seguidas da mesma letra não se diferenciam entre si pelo teste de Tukey a 5\%.

Na Figura 4, estão representados os incrementos anuais em altura das acácias para cada sistema de preparo do solo e para os dois locais de estudo. Observa-se um crescimento mais rápido no primeiro ano em Piratini (1995/96), em Neossolo litólico cascalhento, solo com limitação de profundidade para o crescimento das raízes de espécies florestais, com decréscimo já no segundo ano (1996/97). Em Argissolo Vermelho- 
Amarelo, Butiá, o incremento em altura foi menor no primeiro ano de crescimento e aumentou no segundo ano, para só então haver a diminuição do ritmo de crescimento em altura. Nos dois locais, houve uma queda de crescimento no biênio 1998/2000, em função da competição entre plantas e da ocorrência de chuvas abaixo do normal por um período de dois anos. Esse ritmo de crescimento foi retomado no biênio 2000/02, em função das melhores condições climáticas para o desenvolvimento em Piratini, onde este acompanhamento pôde ser feito.

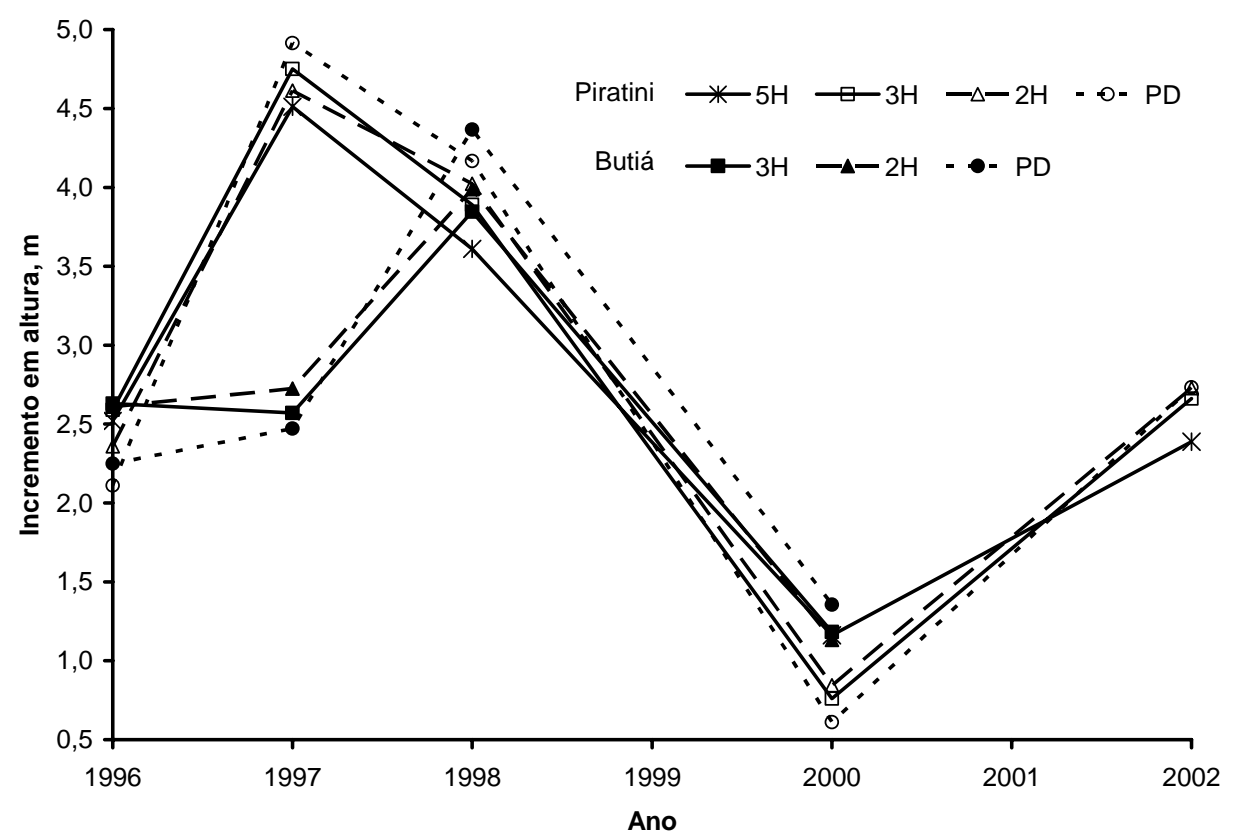

FIGURA 4: Incremento anual em altura das acácias segundo o sistema de preparo do solo em dois locais, Piratini e Butiá, RS; do plantio (1995) ao corte (2002), somente em Piratini, RS.

FIGURE 4: Annual increment in height of black wattle plants growing on different soil tillage systems in two sites, Piratini and Butiá, from planting (1995) to cutting (2002).

Observa-se, também, na Figura 4, que o crescimento inicial das acácias plantadas apenas com a abertura de covas é mais lento inicialmente, em ambos os locais. Já a partir do segundo ano de crescimento, neste sistema de preparo do solo, houve um aumento, que se manteve num ritmo maior que nos demais sistemas de preparo do solo até o corte. Esse início mais lento das plantas, neste sistema de preparo, deve-se, em parte, à competição pela vegetação espontânea, uma vez que as coberturas vegetais, constituídas principalmente de gramíneas, não foram controladas pelo não-revolvimento do solo.

Segundo Larson et al. (2001), a densidade básica é um índice excelente tanto das características anatômicas como das propriedades estruturais da madeira e é o componente mais importante da classificação da qualidade da madeira usada no comércio da madeira de Pinus spp. Em geral, as árvores têm como resposta ao aumento no ritmo de crescimento um aumento na porcentagem de lenho inicial e, em conseqüência, um decréscimo na densidade básica (SIDDIQUI, 1972; BRITO, 1983). Para todos os compartimentos analisados (Tabela 7), as densidades básicas foram maiores nas árvores plantadas apenas pela abertura de covas, concordando com as curvas de incremento anual (Figura 3), que mostram um desenvolvimento inicial mais lento destas acácias. Tais valores de densidade básica foram ainda maiores nas árvores amostradas do plantio comercial, levando-se a supor que o incremento anual, inicialmente, tenha sido ainda mais lento, embora não tenha sido feito o acompanhamento do incremento anual das acácias. Dependendo do destino a ser dado para a madeira das acácias produzidas pode-se considerar qual a estratégia a ser seguida, uma vez que o crescimento inicial mais lento não se transforma em redução significativa de volume de madeira produzida por hectare. 
TABELA 7: Densidade básica dos compartimentos do tronco de acácia negra em amostra tomada na altura do DAP, Piratini, 2002.

TABLE 7: Basic density of trunk compartments of black wattle on samples taken at the DBH, Piratini, 2002.

\begin{tabular}{l|c|c|c}
\hline \multirow{2}{*}{ Sistemas de preparo } & Casca & Cerne & Alburno \\
\cline { 2 - 4 } & \multicolumn{3}{c}{ Densidade Básica $\left(\mathrm{g} \mathrm{cm}^{-3}\right)$} \\
\hline 5H & 0,324 & 0,592 & 0,496 \\
2H & 0,306 & 0,597 & 0,497 \\
Plantio em cova & 0,305 & 0,587 & 0,492 \\
Plantio comercial & 0,330 & 0,618 & 0,526 \\
\hline
\end{tabular}

\section{CONCLUSÕES}

Não houve diferenças significativas de crescimento das acácias plantadas em sistemas distintos de preparo do solo, permitindo, com isto, que se escolha o sistema mais econômico ou mais adequado aos implementos disponíveis, ou menos erosivo.

O crescimento inicial das acácias plantadas em sistema de plantio em covas foi menor do que nos outros sistemas, recuperando-se, nos anos seguintes, nos dois locais estudados.

Dezoito meses após o plantio, as perdas de solo foram insignificantes para qualquer sistema de preparo e locais estudados, em função do rápido crescimento das acácias, com conseqüente cobertura do solo.

As perdas de solo foram maiores nos sistemas de preparo que mobilizaram maior área de solo, mas tiveram comportamento distinto para os diferentes tipos de solo estudados.

As perdas de solo no Neossolo Litólico trazem maior prejuízo para a sustentabilidade deste sítio, porque mais de $50 \%$ do solo é composto por cascalhos ou calhaus, e a sua profundidade efetiva situa-se ao redor de $20 \mathrm{~cm}$ apenas.

O menor crescimento das árvores, seja pela ausência de adubação/correção do solo, seja pelo preparo do solo reduzido, aumentou a densidade básica da casca, alburno e cerne dessas árvores.

\section{REFERÊNCIAS BIBLIOGRÁFICAS}

BRITO, J.O. Influência da adubação mineral nas características dos anéis de crescimento da madeira de Pinus caribea var. bahamensis. 1983. 113f. Dissertação (Mestrado em Engenharia Florestal) - Escola Superior de Agricultura Luiz de Queiroz, Universidade de São Paulo, Piracicaba.

DONKIN, M. J. A multivariate reappraisal of a site evaluation study in Acacia mearnsii De Wild. South African Forestry J., Johannesburg, n. 169, p. 1-10, 1994.

EDESO, J.M.; MERINO, A.; GONZALEZ, M.J. et al. Soil erosion under different harvesting managements in steep forestlands from northern Spain. Land Degradation and Development, New Jersey, v. 10, n. 1, p. 79-88, 1999.

EMBRAPA. Centro Nacional de Pesquisa de Solos. Manual de métodos de análise de solo. Rio de Janeiro: EmbrapaSolos, 1997. v. 1, 210p.

EMBRAPA. Centro Nacional de Pesquisa de Solos. Sistema Brasileiro de Classificação de Solos. Brasília: Embrapa Produção de Informação ; Rio de Janeiro: Embrapa Solos, 1999. 412p.

GATTO, A.; BARROS, N.F.; NOVAIS, R.F. et al. Efeito do método de preparo do solo, em área de reforma, nas suas características, na composição mineral e na produtividade de plantações de Eucalyptus grandis. Revista Árvore, Viçosa, v. 27, n. 5, p. 635-646, 2003.

HILLEL, D. Applications of soil physics. New York : Academic Press, 1980. 385p.

ICFR - Institute for Commercial Forestry Research. Annual Research Report 1991. Pietrmaritzburg : ICFR, 1991. 135p.

LARSON, P; KREISCHMANN, D.E.; CLARK III, A. et al. Formation and properties of juvenile wood in southern pines. A synopsis. Washington: USDA/Forest Service, 2001. 42p. (General Technical Report, FPI-GTR-129).

MAESTRI, R.; GRAÇA, L. R.; SIMÕES, J. W. et al. Análise da adubação fosfatada na produção física e econômica de acácia negra (Acacia mearnsii De Wild). Boletim de Pesquisa Florestal, Colombo, n. 14, p. 39-53, 1987. 
MOREIRA, A.B. Desenvolvimento de máquinas e equipamentos para a utilização em áreas de cultivo mínimo em florestas. In: SEMINÁRIO SOBRE CULTIVO MÍNIMO EM FLORESTAS, 1, Curitiba, 1995. Anais... Colombo: CNPF, 1995. p. 89-105.

PARSONS, D.A. Coshocton-type runoff samplers: laboratory investigations. Washington: USDA/SCS, 1954. 16p. (SCS-TP-124).

MAZUCHOWSKI, J. Z.; DERPSCH, R. Guia de preparo do solo para culturas anuais mecanizadas. Curitiba: Acarpa, 1984. 68p.

SIDDIQUI, K.M. Influence of fertilization on the ultra structure and chemical composition of wood. Syracuse: [s.n.], 1972. 151p.

SILVA, L.L.; SCHNEIDER, P.R.; ELTZ, F.L.F. Influência dos resíduos da colheita da floresta de acácia-negra (Acácia mearnsii De Wild) sobre as perdas de água e solo. Ciência Florestal, Santa Maria, v. 8, n. 1. p. 43-53. 1998.

SIMON, A.A. Produção de mudas de acácia-negra: plantio 1998. Montenegro: TANAGRO, 1999. 3p. (Relatório Técnico).

SPOOR, G. Fundamental aspects of cultivations. In: Soil physical condition and crop production. London: Ministry of Agriculture, 1975. p.128-144. (Technical Bulletin, 29).

STAPE, J.L.; ANDRADE, S.C.; GOMES, A.N. et al. Definição de métodos de preparo de solo para silvicultura em solos coesos do litoral norte da Bahia. In: GONÇALVES, J.L.M.; STAPE, J.L. Conservação e cultivo de solos para plantações florestais. Piracicaba: IPEF, 2002. p.259-296.

TONIETTO, L.; STEIN, P.P. Silvicultura da acácia negra (Acacia mearnsii De Wild) no Brasil. Florestar Estatístico, São Paulo, v. 4, n. 12, p. 11-16, nov.1996/ out.1997.

VÁSQUEZ, S.F. Comportamento inicial da bracatinga (mimosa scabrella Benth.) em consórcio com milho (Zea mays L.) e feijão (Phaseolus vulgaris L.), com e sem aplicação de fertilizantes minerais em solo de campo na região metropolitana de Curitiba, PR. 1987. Dissertação (Mestrado em Engenharia Florestal) - Universidade Federal do Paraná, Curitiba.

VITAL, B.R.; PEREIRA, A.R.; DELLA LUCIA, R.M. et al. Efeito da idade da arvore na densidade da madeira de Eucalyptus grandis cultivado na região de cerrado de Minas Gerais. Brasil Florestal: Boletim Tecnico, Brasilia, n.8, p.49-52, ago. 1984. 